\title{
Pelatihan Pembuatan Aplikasi Alat Tes Menggunakan Macromedia Flash dan Google Forms Bagi Konselor Sekolah
}

\author{
Dydik Kurniawan $^{1 *}$, Tri Wahyuningsih ${ }^{2}$, Huzaifah Umar ${ }^{3}$, Ridho Kani Lestari ${ }^{4}$ iD \\ 1,2,3 Program Studi Bimbingan dan Konseling, FKIP Universitas Mulawarman Indonesia \\ *Corresponding author: dydik.kurniawan@fkip.unmul.ac.id
}

\begin{abstract}
Abstrak
Pelaksanaan bimbingan dan konseling di beberapa sekolah masih dilakukan secara manual sehingga membutuhkan waktu dan biaya yang cukup mahal. Pelatihan ini dilaksanakan dengan maksud agar pembuatan program Bimbingan dan Konseling disekolah dapat terlaksana selama masa pandemik Covid 19, sehingga pelaksaan program yang dibuat berjalan dengan baik. Pelatihan dilaksanakan selama 3 hari dengan diikuti 25 peserta, pelaksanaan pelatihan ini dilaksanakan secara Daring. Hasil dari pelatihan mampu meningkatkan pengetahuan dan keterampilan guru dalam pembeuatan instrument (alat tes)menjadi lebih menarik serta berbasis online yang dapat menjadi solusi di masa pandemik covid 19, dengan memanfaatkan instrument (alat tes) tersebut tugas para guru Bimbingan dan Konseling akan lebih efektif dan efisien. Kesimpulan Hasil kegiatan terjadinya Peningkatan Kompetensi guru mengoptimalkan pembuatan aplikasi alat tes memanfaatkan macromedia flash dan google forms.
\end{abstract}

Kata Kunci: Alat Tes, Macromedia Flash, Google Form

\section{Abstract}

In North Sam tools usingarinda Subdristrict, by conducting workshops on making onlinebased ools using Macromedia Flash and Google Type, to develop the skills of Guidance and Counseling Teachers in making Guidance and Counseling instrument applications (test kits). This training is being conducted with the goal of implementing the Guidance and Counseling program in schools during the Covid 19 pandemic so that the program's installation runs smoothly.The training took place over a span of 3 day with the participation of 25 learners and the online implementation of the training was carried out. The results of the training were able to increase the teachers awareness and skills in making resource (test kits) more attractive and online-based, which could be a solution to the covid 19 pandemic. By using these instruments, the function of teacher guidance and therapy will be more productive and successful. An improvement in the awareness and skill of teachers in making test tool applications using Macromedia Flash and Google Form is the conclusion ofe the results achieved by this activity.

Keywords: instrument, Macromedia Flash, Google Forms

\section{INTRODUCTION}

Di era modern seperti saat ini perkembangan teknologi informasi dan komunikasi sudah semakin canggih dan tidak dapat dihindari. Dimana dalam perkembangannya teknologi telah mempengaruhi seluruh aspek kehidupan baik itu aspek ekonomi, sosial, budaya, sampai pada aspek pendidikan (Cahyawulan et al., 2019; Setiawan, 2018). Pengunaan teknologi dalam bidang pendidikan akan dapat meningkatkan keberhasilan serta meningkatkan kompetensi guru serta siswa (Gunawan et al., 2020). Untuk mengimbangi perkembangan teknologi di dunia pendidikan, guru dituntut untuk mampu memanfaatkan teknologi dengan baik. Tidak hanya guru bidang studi, guru BK juga dituntut untuk mampu menggunakan teknologi dalam melakukan evaluasi terhadap prilaku siswa. Guru BK harus selalu dapat meningkatkan Kompetensi dalam pemanfaat TIK, dimana TIK dapat digunakan untuk mendukung Layanan BK di sekolah, sehingga para siswa dan siswi dapat menerima secara

$\begin{array}{ll}\text { History: } & \\ \text { Received } & \text { : April 07, } 2021 \\ \text { Revised } & \text { : April 09, } 2021 \\ \text { Accepted } & \text { : May 08, } 2021 \\ \text { Published } & \text { : May 10, } 2021\end{array}$


maksimal dari layanan BK (Basri, 2018; Triyono et al., 2019).

Namun kenyataan dilapangan dari data kualitatif yang diperoleh melalui hasil wawancara dengan beberapa perwakilan guru MGMP BK ini khususnya Guru-guru BK di wilayah Kecamatan Samarinda Utara, sebagian besar guru BK masih mengalami kendala dalam pemanfaatan Teknologi Informasi dan Komunikasi (TIK) dalam layanan Bimbingan dan Konseling di sekolah. Salah satu contoh yang terjadi di sekolah yaitu masih sebagian besar ditemukannya Guru BK menggunakan angket berbasis kertas (paper-based) saat melakukan asesmen ke siswa dan evaluasi Bimbingan dan Konseling. Dengan menggunakan berbasis kertas memerlukan biaya untuk diprint, angket yang masih menggunakan kertas memerlukan waktu yang cukup lama untuk pengumpulan datanya serta menginput data tersebut. Asesmen dan evaluasi Bimbingan dan Konseling pada tahapan penginputan data dari peserta didik sangat menyita waktu karena masih dikerjakan secara manual. Hal tersebut menjadi alasan mengapa asesmen dan evaluasi merupakan kegiatan yang sering tidak optimal pada pelaksanaannya bahkan tidak dilaksanakan sama sekali. Permasalahan tersebut dapat menjadi indikasi bahwa kompetensi Teknologi Informasi dan Komunikasi (TIK) guru BK perlu menjadi perhatian khusus agar dapat ditingkatkan secara maksimal, sehingga program yang dibuat oleh guru BK tepat sasaran. Dalam mengatasi permasalahan-permasalahan terkhusus dalam alat tes yang berbasis paper harus ada alternatif yang diberikan yaitu dialihkan ke dalam aplikasi, untuk itu perlu adanya pengembagan alat tes berbasis Online dengan mengunakan Google Forms yang dikombinasikan dengan Macromedia Flash, dengan tujuan agar kinerja dari guru BK menjadai lebih efektif dan efisien baik dalam menginput data, merekap dan menganalisi hasil dari pesertadidik, sehingga Program kerja Bimbingan dan Konseling guru BK menjadi maksimal di sekolah. Pembuatan alat tes berbasis online merupakan Salah satu alternatif di masa pandemik covid-19 yang melanda diseluruh indonesia, agar Program Guru Bimbingan dan Konseling yang ada di sekolah tetap berjalan dengan baik.

Google Form adalah situs yang berbasis web yang memungkinkan setiap orang dapat memberikan tanggapan atau jawaban terhadap kuis ataupun kuisioner secara cepat dimanapun ia berada dengan menggunakan aplikasi internet komputer/laptop ataupun Handphone (Parinata \& Puspaningtyas, 2021). Penggunaan aplikasi google form memungkinkan guru dapat membuat soal kuis atau ujian secara online, dan dapat membagikan soal tersebut dalam bentuk link melalui smarphone (Yuwono et al., 2020). Melalui google form siswa dapat mengerjakannya melalui smartphone dan dapat langsung mengetahui skor yang diperoleh serta mengetahui mana jawaban yang benar dan jawaban yang salah secara otomatis (Iqbal et al., 2018). Aplikasi google form memiliki format/tampilan yang cukup sederhana dan menoton, sehingga kurang menarik minat siswa dalam proses pengisian kuisioner atau kuis. Untuk mempercantik tampilan pada google form maka aplikasi ini dapat digabungkan dengan aplikasi lainnya seperti aplikasi Macromedia Flash. Macromedia Flash merupakan program grafis yang diperuntukan untuk motion atau gerak dan dilengkapi dengan script untuk programming (action script) dengan program ini memungkinkan pembuatan animasi media interaktif yang dapat menarik perhatian siswa sata belajar (Wirasasmita \& Putra, 2017).

Dalam pemberian layanan bimbingan dan konseling, penggunaan aplikasi yaitu software Macromedia Flash yang dikombinasikan dengan google Forms dapat membantu memudahkan pelaksanaan, pengumpulan, dan pengadmintrasian layanan assesmen dan evaluasi BK. Oleh karena itu, peningkatan kompetensi guru BK dalam memanfaatan aplikasi atau teknologi berbasis internet yang berguna memudahkan perluasan akses layanan BK di sekolah menjadi signifikan untuk dilakukan (Imawanty \& Fransiska, 2019; Triyono et al., 2019). Minimnya pemahaman dan keterampilan teknologi tersebut akan diatasi dengan pelatihan pembuatan aplikasi alat tes menggunakan software Macromedia Flash dan google 
Forms. Tujuan Pelatihan ini memaparkan pentingnya kompetensi Teknologi Informasi dan Komunikasi (TIK) dalam pemberian layanan bimbingan dan konseling serta mejelaskan bahwa Guru BK yang bertugas dikecamatan samarinda utara dapat memanfaatkan Teknologi Informasi dan Komunikasi (TIK) agar dapat memaksimalkan implementasi layanan bimbingan dan konseling, khususnya asesemen dan evaluasi bimbingan dan konseling, yang selama ini merupakan tanggungjawab pengadministrasian dari Guru BK. Dari pelatihan ini yang dapat dipelajari dan diimplementasikan oleh Guru BK dalam peningkatan kompetensi Teknologi Informasi dan Komunikasi (TIK) adalah bagaimana Guru BK memanfaatkan berbagai aplikasi Formulir (software) daring yang dapat dimanfaatkan secara maksimal guna membantu dan memudahkan pengadministrasian pengumpulan data pada kegiatan asesmen dan evaluasi.

Harapan kedepan dari kegitan ini dapat dijadikan pertimbangan oleh berbagai pihak khususnya pihak sekolah dan dinas pendidikan agar dapat melaksanakan kegiatan serupa dalam rangka meningkatkan kompetensi dan memanfaat secara maksimal TIK oleh guru BK ( Triono, dkk : 2018). Berdasarkan Penjelasan di atas kegiatan ini bermaksud membuat sebuah aplikasi Instrumen (alat tes) yang dapat membantu terkhususnya guru Bimbingan dan Konseling untuk memfasilitasi para siswa secara lebih mudah dan fleksibel, maka penulis memilih kegiatan "Pelatihan Pembuatan Aplikasi Alat Tes Dengan Menggunakan Macromedia Flash dan google Forms bagi Konselor Sekolah"

\section{MATERIALS AND METHODS}

Kegiatan pelatihan pembuatan aplikasi alat tes dengan menggunakan macromedia flash dan google forms bagi konselor sekolah dilakukan dengan melibatkan seluruh guru Bimbingan dan Konseling Se-Kecamatan Samarinda Utara yang berjumlah 25 orang. Kegiatan ini dilaksanakan selama 1 hari secara daring, dikarenakan adanya pandemi covid19. Pelaksanaan Metode yang telah dilaksanakan dalam kegiatan masyarakat meliputi kegiatan persipan, pelaksanaan dan kegiatan evalusi. Pada tahap persiapan dilakukan proses pembuatan surat perijinan pelaksanaan dan berkoordinasi dengan FKIP UNMUL, membuat Surat Perijinan dengan dinas Pendidikan Kota Samarinda, dan Membuat Surat Perijinan dengan dinas Pendidikan Provinsi Kalimantan Timur. Setelah diperoleh perijinan dan tahap persiapan telah dirasa cukup, maka kegiatan dilaksanakan pada tahap pelaksanaan. Tahap pelaksanaan dimulai dari kegiatan Pelatihan yang meliputi: Kegiatan pembukaan yang dihadiri dan dibuka oleh perwakilan dari dinas Pendidikan Provinsi Kalimantan Timur yang kemudian dilanjutkan dengan memberikan orientasi berupa pemberian materi macromedia flash dan google forms, menjelaskan dan mempraktikan pembuatan aplikasi menggunakan macromedia flash, menjelaskan dan mempraktikan secara langsung pembuatan instrumen aum menggunakan google forms, mempraktikkan mensingkronkan google forms ke macromedia flash, dan tanya jawab untuk meningkatkan pemahaman tentang pembuatan instrumen (alat tes) berbasis macromedia flash dan google forms. Dan tahap pelaksanana yang terakhir yakni tahap evaluasi, yang dilaksanakan untuk mengetahui keberhasilan dari program pelatihan dalam Pembuatan Instrument (Alat Tes) menggunakan aplikasi Macromedia Flash dan Google Forms ditinjau dari produk yang telah dibuat peserta, wawancara dengan Peserta dan keaktifan peserta.

\section{RESULTS AND DISCUSSION}

Pada tahapan persiapan dilaksanakan proses pembuatan surat dan pengumpulan ijin pelaksanaan kegiatan serta observasi terhadap kondisi lapangan. Hasil dari tahapan persiapan menunjukkan hasil bahwa, panitia pelaksana kegiatan pendampingan guru BK, diijinkan 
untuk melaksanakan kegiatan secara daring melalui platform zoom meeting. Selanjutnya berdasarkan hasil berdasarkan hasil identifikasi atau need assesment terhadap permasalahan yang terjadi selama ini, dan hasil analisis potensi sekolah didapatkan informasi pula bahwa pelaksanaan assessment oleh guru BK masih dilakukan secara manual dengan menggunakan paper/kertas yang membutuhkan biaya dalam proses percetakan serta membutuhkan waktu yang cukup lama dalam proses perekapan hasil. Sehingga berdasarkan permasalahan tersebut dikenalkanlah aplikas web berupa google form yang berbasis berbasis macromedia flash.

Dalam proses pelaksanaan program guru BK dikenalkan dan dijelaskan mengenai fungsi menu-menu dan tools software-software yang ada pada google form dan berbasis macromedia flash. Kegiatan dilaksanakan dengan memberikan arahan, penjelasan dan pelatihan terkait dengan bagaimana cara penggunaan software Macromedia Flash bagi para peserta. Kegiatan ini dilakukan melalui pemberian pelatihan pembuatan alat tes online dengan menggunakan Google Forms. Pemberian teori dilakukan dalam satu hari kegiatan pelaksanaan pada tanggal 19 November 2020 secara virtual melalui Zoom. Selain itu dalam proses pelaksanaan peserta juga didemonstrasikan mengenai cara penggunaan software Macromedia Flash dan Google Forms yang telah dibuat dan bagaimana mengimport hasil yang diperoleh untuk dapat dianalisis Oleh Guru Bimbingan dan Konseling.

Hasil dari tahap pelaksanaan program menunjukkan bahwa para peserta sangat antusias dalam mengikuti kegiatan pelatihan, sehingga terdapat peningkatan pengetahuan dan kompetensi pserta baik dalam hal mendisain media macromedia flash dan memanfaat google form secara maksimal, bagaimana menganalisis secara efektif dan efisiean dengan mengeksport fiel kedalam bentuk excell sehingga dapat langsung dapat diperoleh hasilnya. Evaluasi terhadap proses pelaksanaan dapat dilakukan dengan melihat kualitas produk yang telah selesai dibuat oleh peserta. Produk yang dihasilkan dari kegiatan adalah alat tes need asessment menggunakan software Macromedia Flash dan Google Forms. Namun dari kegiatan Pelatihan ada beberapa hal yang perlu diamati dari kegiatan pelatihan meliputi kendala-kendala yang terjadi, kekurangan-kekurangan, dan kelemahan-kelemahan yang muncul dalam proses pembuatan aplikasi ini. Kendala yang dihadapi sebagian besar peserta dalam pembuatan alat tes need asessment berbasis Macromedia Flash dan Google Forms adalah dalam penguasaan tools-tools Macromedia Flash dan Google Forms banyak dari peseta masih kurang terampil dalam pemanfaatan tools yang ada pada software. Namun melalui pelatihan yang dipandu secara perlahan dan dilakukan pengulangan dalam penjelasan oleh fasilitator, peserta dapat memahami fungsi dan manfaat dari tools Macromedia Flash dan Google Forms, sehingga produk dari media alat tes dapat dibuat dengan baik mengikuti arahan dari narasumber. Evaluasi dilakukan terhadap kemampuan peserta dalam menyusun media alat tes need asessment, mendisain agar menarik dan implementasinya guna mendukung Layanan Bimbingan dan Konseling kedepan. Kegiatan Refleksi juga dilakukan pada pelatihan ini dengan tujuan untuk mengetahui kekurangan maupun kelebihan kegiatan pengabdian yang telah dilakukan, agar dapat memberikan rekomendasi terhadap keberlangsungan atau pengembangan kegiatan berikutnya. Dari hasil refleksi perlu dilakukan tindak lanjut untuk membantu dalam meningkatkan penguasaan guru terhadap Ilmu Pengetahuan dan Teknologi terutama dalam penerapannya pada Layanan Bimbingan dan Konseling yang dikolaborasikan dengan Pemanfaatan Teknologi Informasi dan Komunikasi.

Secara umum pelaksanaan kegiatan pengabdian dengan pesertanya guru-guru Bimbingan dan Konseling di Samarinda telah terlaksana dengan baik. Dalam kegiatan pelatihan dapat dilihat atusias peserta dalam mengikuti pelatihan sangat tinggi, dan pelatihan yang telah dilaksanakan ini merupakan kegiatan pertama kali para peserta dalam mendisain sampai membuat alat tes secara berbasis online dengan menggunakan Macromedia Flash dan Google Forms (Coupey, 2001). Hal ini mengindikasikan bahwa para peserta menyambut positif kegiatan tersebut, walaupun pelaksanaan kegiatan dilakukan secara daring 
menggunakan aplikasi zoom. Sesuai dengan apa yang diharapan pihak sekolah, terhadap kegiatan pelatihan ini agar dapat memberikan memberi penyegaran atau mengupdate bagi para guru Bimbingan dan Konseling di sekolah khususnya dalam memanfaat teknologi, baik terkait dengan pendalaman materi Bimbingan dan Konseling khususnya alat tes dan non tes, serta pemanfaat teknologi khususnya mengoptimalkan google form dan macromedia flash yang dikolaborasikan dengan Intrumen alat tes yang digunakan untuk need assesment. Setelah instrumenneed assesment selesai dibuat berbasis online dapat dimanfaatkan oleh guru BK dalam mendukung program.

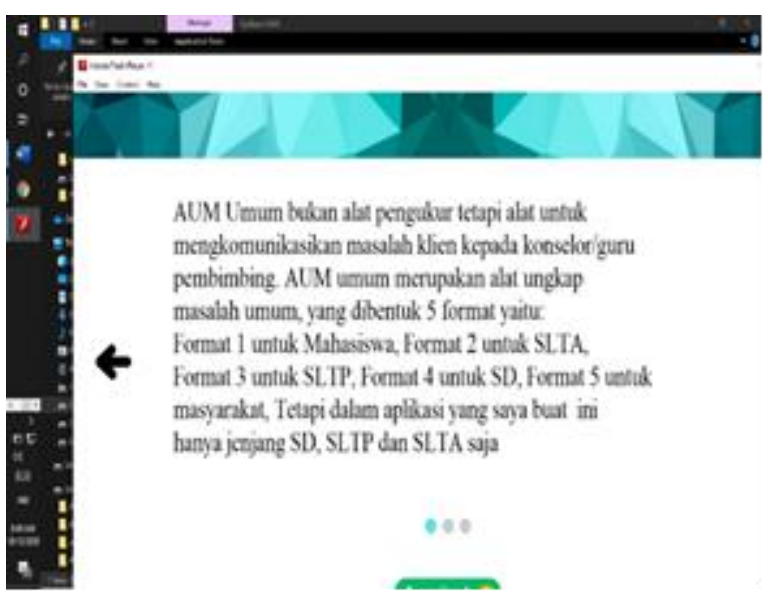

Gambar 1. Tampilan Aplikasi instrument

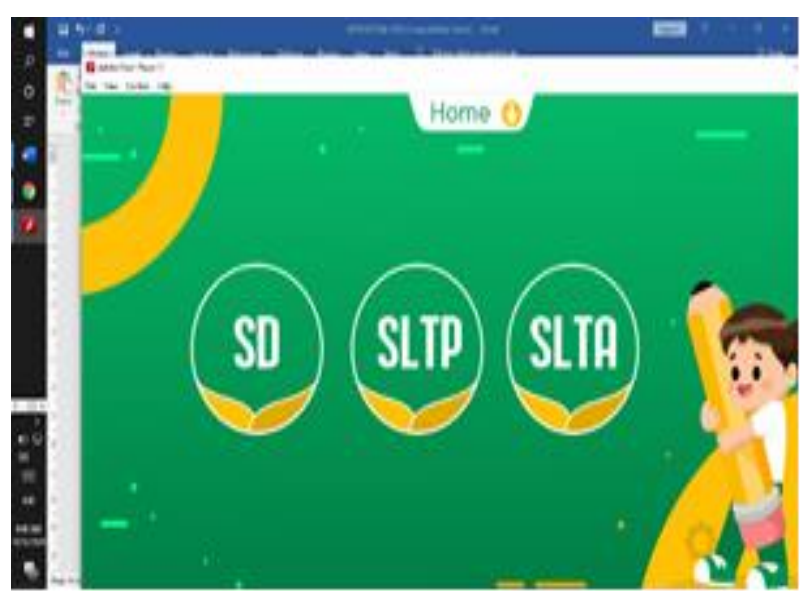

Gambar 2. Aplikasi instrument

Kegiatan ini berbeda dengan kegiatan yg sudah pernah dilaksanakan sebelumnya, dimana kegiatan sebelumnya hanya memanfaatkan google form, tetapi kegiatan yang sudah kami lakukan dengan menkolaborasikan aplikasi macromedia flash dengan google form dengan harapan menjadi lebih kreatif dan inovatis dari produk yang dihasil kan oleh para peserta. Dengan adanya pelatihan ini para peserta dapat mengembangkannya dalam pemanfaatan yang lain seperti pendataan pesertadidik, pengerjaan LKPD (lembar Kerja Peserta didik), dll. Pihak sekolah dan para peserta menyambut antusias terkait pelaksanaan pelatihan dan berharap pelaksanaan pelatihan dapat dilakukan secara kontinu untuk membantu meningkatkan kualitas kompetensi guru-guru Bimbingan dan Konseling di masa pandemik ini, sehingga dapat bermanfaat secara maksimal dalam melaksanakan salah satu program dari Bimbingan dan Konseling. Kepala Sekolah mengharapkan nantinya ada pelatihan yang sama guna membimbing guru-guru mapel lainnya sehingga dapat meningkatkan kreatifitas dan inovasi dari guru mapel yang ada di sekolah. Dengan demikian kegiatan pengabdian ini telah berlangsung dengan baik.

\section{CONCLUSION}

Hasil dari pelatihan adalah sebagai berikut: Dalam pelaksanaan kegiatan pengabdian masyarakat berupa pelatihan Pembuatan instrumen Bimbingan dan Konseling Menggunakan Macromedia Flash Google Forms telah berlangsung dengan baik, dengan dihadiri oleh 25 orang $(89,3 \%)$ dan seluruh peserta mengikuti pelatihan secara penuh. Dari kegiatan pelatihan ini adanya Peningkatan pengetahuan dan keterampilan para guru Bimbingan dan konseling dengan baik saat Pembuatan Aplikasi Alat Tes Dengan Menggunakan Macromedia Flash dan Google Forms. Produk Aplikasi Alat Tes Menggunakan Macromedia Flash Google Forms berbasis online menjadi solusi selama pademik covid 19. 


\section{REFERENCES}

Basri, S. H. (2018). Urgensi Penggunaan Teknologi Media Dalam Implementasi Bimbingan Dan Konseling Di Sekolah. Jurnal Al Isyraq, 1(1), 83-107. http://alisyraq.pabki.org/index. php/alisyraq/article/view/6/8.

Cahyawulan, W., Badrujaman, A., Fitriyani, H., Mamesah, M., Eka, Wahyuni, \& Djunaedi. (2019). Peningkatan Kompetensi Teknologi dan Informasi Guru Bimbingan dan Konseling. Jurnal Pengabdian Kepada Masyarakat, 1(3), 195-199. https://doi.org/10.31960 /caradde.v1i2.76.

Coupey, E. (2001). Marketing and The Internet. Prentice Hall.

Gunawan, I. G. D., Pranata, Paramarta, I. M., Mertayasa, I. K., Pustikayasa, I. M., \& Widyanto, I. P. (2020). Peningkatan Mutu Kompetensi Guru Sekolah Dasar Dalam Menyongsong Era Society 5.0. Prosiding Webinar Nasional IAHN-TP Palangka Raya, $\quad$ 15-30. http://prosiding.iahntp.ac.id/index.php/seminarnasional/article/view/34/29.

Imawanty, \& Fransiska, A. B. (2019). Guru Bimbingan Dan Konseling Berkualitas Di Era Revolusi 4.0 : Pembelajar, Kompeten, Dan Up To Date. Prosiding Seminar Nasional Pendidikan FKIP, 2(1), 147-153. https://jurnal.untirta.ac.id/index.php/psnp/article/view /5726/4108.

Iqbal, M., Amal, B. K., \& Rumapea, M. E. (2018). Penggunaan Google Forms Sebagai Media Pemberian Tugas Mata Kuliah Pengantar Ilmu Sosial. Urnal Pendidikan IlmuIlmu Sosial, 10(1), 120-127. http://alisyraq.pabki.org/index.php/alisyraq/article/view/6/8.

Parinata, D., \& Puspaningtyas, N. D. (2021). Optimalisasi Penggunaan Google Form terhadap Pembelajaran Matematika. Mathema Journal, 3(1), 56-65. https://ejurnal.teknokrat.ac.id /index.php/jurnalmathema/article/view/1008/543.

Setiawan, D. (2018). Dampak Perkembangan Teknologi Informasi dan Komunikasi Terhadap Budaya. JURNAL SIMBOLIKA: Research and Learning in Communication Study, 4(1), 62. https://doi.org/10.31289/simbollika.v4i1.1474.

Triyono, Febriani, R. D., Hidayat, H., \& Putri, B. N. D. (2019). Pelatihan penggunaan teknologi informasi kepada guru bimbingan dan konseling. Jurnal PKM Ilmu Kependidikan, 2(1). https://doi.org/http://dx.doi.org/10.31851/dedikasi.v1i2.2829.

Wirasasmita, R. H., \& Putra, Y. K. (2017). Pengembangan Media Pembelajaran Video Tutorial Interaktif Menggunakan Aplikasi Camtasia Studio Dan Macromedia Flash. Jurnal Pendidikan Informatika, 1(2), 35-43.

Yuwono, M. R., Aribowo, E. K., Firmansah, F., \& Indrayanto, B. (2020). Pelatihan Anbuso, Zipgrade, Dan Google Form Sebagai Alternatif Penilaian Pembelajaran Di Era Digital. Jurnal Pengabdian Masyarakat, 3(3). https://doi.org/10.31604/jpm.v3i1.4960. 